\title{
Synthesis of Mg/Al Hydrotalcite by Using Low Supersaturated Precipitation Method with Variation of Mole Ratio
}

\section{Christanty Wahyu Septyaningrum, Sri Handayani, Cahyorini Kusumawardani, Kun Sri Budiasih}

\author{
Jurusan Pendidikan Kimia, FMIPA Universitas Negeri Yogyakarta \\ e-mail:irienuny@yahoo.com,handayani137uny@yahoo.com,ks_budiasih@yahoo.co.uk
}

\begin{abstract}
This research aims to synthesize $\mathrm{Mg} / \mathrm{Al}$ hydrotalcite with mole ratio variations of $\mathrm{Mg} / \mathrm{Al}$ precursor through low supersaturated precipitation method. $\mathrm{Mg} / \mathrm{Al}$ hydrotalcite was synthesized with $\mathrm{Mg} / \mathrm{Al}$ mole ratio variation of $1: 1,2: 1,3: 1$, and 4:1. $\mathrm{Mg} / \mathrm{Al}$ hydrotalcite was synthesized using $\mathrm{NaOH}$ and $\mathrm{Na}_{2} \mathrm{CO}_{3}$ base solutions. The mixture of precursor was stirred for 2 hours then treated by hydrothermal at $100{ }^{\circ} \mathrm{C}$ for 4 hours. Results of the synthesis $\mathrm{Mg} / \mathrm{Al}$ hydrotalcite with mole ratio variations is a white powder. The formation of the structure of $\mathrm{Mg} / \mathrm{Al}$ hydrotalcite showed by certain peaks in the FTIR spectra and XRD diffractogram.

The results of data analysisshowed that variation of mole ratio $\mathrm{Mg} /$ Alcauses a shift of peak in the XRD diffractogram shifted towards the left along with a comparative increase in mole ratio $\mathrm{Mg} / \mathrm{Al}$, but the main functional groups on the compound $\mathrm{Mg} / \mathrm{Al}$ hydrotalcite increasingly formed with better.
\end{abstract}

Keywords: $\mathrm{Mg} / \mathrm{Al}$ hydrotalcite, low supersaturated precipitation method, hydrothermal.

\begin{abstract}
ABSTRAK
Penelitian ini bertujuan untuk mengetahui pengaruh variasi perbandingan mol $\mathrm{Mg} / \mathrm{Al}$ terhadap karakter struktur senyawa hidrotalsit $\mathrm{Mg} / \mathrm{Al}$. Hidrotalsit $\mathrm{Mg} / \mathrm{Al}$ disintesis dengan perbandingan mol $\mathrm{Mg} / \mathrm{Al}$ 1:1, 2:1, 3:1, dan 4:1. Sintesis menggunakan larutan basa $\mathrm{NaOH}$ dan $\mathrm{Na}_{2} \mathrm{CO}_{3}$. Campuranprekursor yang telahdiadukselama2 jam ini kemudian dihidrotermal pada temperatur $100^{\circ}$ Cselama 15 jam. Hasil sintesis pada variasi mol hidrotalsit $\mathrm{Mg} / \mathrm{Al}$ berupa serbuk berwarna putih. Terbentuknya struktur hidrotalsit $\mathrm{Mg} / \mathrm{Al}$ ditandai dengan adanya puncak-puncak pada spektra FTIR dan difraktogram XRD.

Hasil analisis data menunjukkan bahwa variasi perbandingan mol $\mathrm{Mg} / \mathrm{Al}$ menyebabkan terjadinya pergeseran puncak pada difraktogram XRD bergeser kearah kiri seiring dengan meningkatnya rasio mol Mg/Al, akan tetapi gugus-gugus fungsi utama pada senyawa hidrotalsit $\mathrm{Mg} / \mathrm{Al}$ semakin tidak terbentuk dengan baik.
\end{abstract}

Kata kunci: hidrotalsit $\mathrm{Mg} / \mathrm{Al}$, metode presipitasi tak jenuh, hidrotermal.

\section{Pendahuluan}

Hidrotalsit merupakan material yang banyak digunakan sebagai padatan pendukung katalis, adsorben, penukar anion, penangkap anion, dan stabilizer.
Rumus umum hidrotalsit adalah $\left[\mathrm{M}_{1-}\right.$ $\left.{ }_{\mathrm{x}}^{2+} \mathrm{M}_{\mathrm{x}}{ }^{3+}(\mathrm{OH})_{2}\right]^{\mathrm{b}-}\left[\mathrm{A}^{\mathrm{n}}\right]_{\mathrm{b} / \mathrm{n}} \cdot \mathrm{mH}_{2} \mathrm{O} \cdot \mathrm{M}^{2+}$ dan $\mathrm{M}^{3+}$ adalah kation divalen dan trivalen dengan kisaran x normal antara 0,17 sampai $0,33 \cdot \mathrm{A}^{\mathrm{n}-}$ adalah anion organik atau anorganik pada 
antar lapis dengan muatan negatif yang dapat dipertukarkan. Parameter b merupakan muatan lapisan sedangkan $\mathrm{m}$ merupakan jumlah molekul $\mathrm{H}_{2} \mathrm{O}$. Selain itu bagian antar lapis pada hidrotalsit berisi anion dan air yang bersifat bebas berpindah dengan memutus ikatannya dan membentuk ikatan baru. Air tersebut dapat dieliminasi tanpa merusak struktur inti hidrotalsit.

Sintesis katalis hidrotalsit dapat dilakukan dengan preparasi metode kopresipitasi yang melibatkan proses titrasi,presipitasi pada larutan jenuh (high supersaturation)ataupun pada larutan encer (low supersaturation) yang dilakukan melalui peningkatan $\mathrm{pH}$.

Pada sintesis hidrotalsit dengan metode presipitasi, terdapat beberapa parameter yang mempengaruhi karakter hidrotalsit variasi jumlah mol $\mathrm{Mg} / \mathrm{Al}$ yang dihasilkan, antara lainperbandingan jumlah mol $\mathrm{Mg} / \mathrm{Al}$. Kishore dan Kannanmenyebutkan bahwa katalis hidrotalsit $\mathrm{Mg} / \mathrm{Al}$ dengan perbandingan 4:1 mampu memberikan aktivitas maksimum sebagai suatu katalis yang baik.

Penelitian tentang variasi mol $\mathrm{Mg} / \mathrm{Al}$ dalam suatu sintesis diperlukan untuk mempelajari pengaruh variasi perbandingan mol Mg/Al terhadap karakter struktur senyawa hidrotalsit $\mathrm{Mg} / \mathrm{Al}$.

\section{Tujuan Penelitian}

Tujuan penelitian ini adalah sebagai berikut: Mengetahui pengaruh variasi perbandingan mol $\mathrm{Mg} / \mathrm{Al}$ terhadap karakter struktur senyawa hidrotalsit $\mathrm{Mg} / \mathrm{Al}$.

\section{Metode Penelitian}

Sebanyak 1,2821 g magnesium nitrat dan 1,9042 g alumunium nitrat masingmasing dilarutkan dalam $100 \mathrm{~mL}$ akuabides dengan gas $\mathrm{N}_{2}$ dan diaduk selama 15 menit. Kedua larutan dicampur dan diaduk selama 30 menit. Campuran 1,4141 g NaOH dan 3,7283 $\mathrm{g} \mathrm{Na}_{2} \mathrm{CO}_{3}$ dilarutkan dalam $50 \mathrm{~mL}$ akuabides, kemudian ditambahkan ke dalam campuran larutan $\mathrm{Mg} / \mathrm{Al}$. Nilai $\mathrm{pH}$ pada larutan ini berkisar 9-11. Campuran larutan dimasukkan ke dalam botol teflon,dihidrotermal $100^{\circ} \mathrm{C}$ selama 15 jam. Padatan yang diperoleh dipisahkan dan dicuci.Hasil padatan dikeringkan pada temperatur $\quad 80^{\circ} \mathrm{C}$ selama 15 jam. Menggunakan prosedur yang sama dilakukan variasimolMg/Al pada perbandingan mol 2:1, 3:1, dan 4:1. Karakterisasi katalis hidrotalsit $\mathrm{Mg} / \mathrm{Al}$ dengan menggunakan X-ray difraktometer dan Spektroskopi Infra-Merah.

\section{Pembahasan}

Hasil sintesis hidrotalsit $\mathrm{Mg} / \mathrm{Al}$ dengan variasi rasio mol 1:1, 2:1, 3:1, 4:1 kemudian 
dianalisis karakter struktur senyawanya dengan puncak melebar pada daerah 3400dengan menggunakan Spektroskopi Fourier $3500 \mathrm{~cm}^{-1}$ yang menunjukkan adanya vibrasi Transform Infrared (FTIR) dan X-ray ulur O-H dari gugus hidroksi di dalam difraktometer (XRD). lembaran-lembaran Mg/Alhydro-talcite-like

Hasil analisis FTIR pada variasi rasio dengan molekul-molekul air dalam partikel mol senyawa hidrotalsit $\mathrm{Mg} / \mathrm{Al}$ ini dilakukan atau dalam antar lapis semakin datar semakin pada bilangan gelombang $400-4000 \mathrm{~cm}^{-1}$ tidak terbentuk dengan bertambahnya variasi untuk mengidentifikasi gugus-gugus fungsi mol pada material hidrotalsit, sehingga yang terdapat di dalam material hitrotalsit $\mathrm{Mg} / \mathrm{Al}$, yaitu seperti adanya gugus fungsi dari ion hidroksida $\left(\mathrm{OH}^{-}\right)$, ion karbonat $\left(\mathrm{CO}_{3}{ }^{2-}\right)$, dan puncak-puncak pada ikatan $\mathrm{O}-$ $\mathrm{H}, \mathrm{C}-\mathrm{O}, \mathrm{Mg}-\mathrm{O}$, dan Al-O. serapan pada daerah sekitar $1650 \mathrm{~cm}^{-1}$ yang menunjukkan adanya tekukan $\mathrm{OH}$ yang berasal dari molekul air pada daerah antar lapis yang terikat dengan anion interlayer pun juga semakin tidak terbentuk.

Berdasarkan spektra FTIR (Gambar 1)

dapat dikatakan bahwa adanya serapan

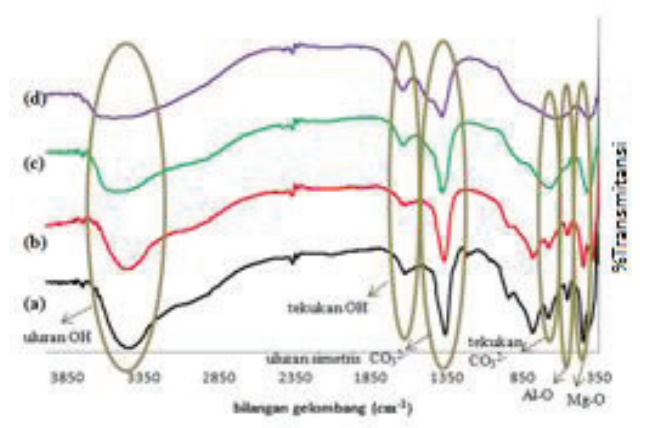

Gambar 1. Spektra FTIR senyawa hidrotalsit Mg/Al (a)1:1 (b)2:1 (c)3:1 (d) 4:1

Semakin besar variasi mol pada hidrotalsit $\mathrm{Mg} / \mathrm{Al}$ 4:1. Hasil penelitian material hidrotalsit ini menunjukkan uluran simetris $\mathrm{O}=\mathrm{C}-\mathrm{O}$ pada daerah $1385 \mathrm{~cm}^{-1}$ juga semakin tidak terbentuk. Pada daerah 650 $\mathrm{cm}^{-1}$ menunjukan adanya tekukan $\mathrm{O}=\mathrm{C}-\mathrm{O}$ dari $\mathrm{CO}_{3}{ }^{2-}$ juga semakin tidak terbentuk, ini dimulai pada hidrotalsit $\mathrm{Mg} / \mathrm{Al}$ 3:1 dan vibrasi uluran Mg-O terdapat pada daerah

Davydov (1984) dan Shiddiq (2005) dalam Heraldy dkk menyebutkan bahwa puncak pada daerah $\pm 550 \mathrm{~cm}^{-1}$ merupakan uluran AlO sehingga puncak pada daerah $555,50 \mathrm{~cm}^{-1}$ menunjukan adanya vibrasi uluran Al-O dan 
400-416 $\mathrm{cm}^{-1}$. Gugus $\mathrm{Mg}-\mathrm{O}$ dan Al-O ditunjukan pada 2 puncak yang saling berdekatan, namun semakin besar variasi mol pada material hidrotalsit ini puncak $\mathrm{Mg}-\mathrm{O}$ maupun Al-O semakin tidak terbentuk jelas.

Berdasarkan dari data JCPDS nomor 22-0700 menunjukkan bahwa tiga puncak tertinggi pada nilai $2 \theta=11,4^{\circ} ; 22,7^{\circ}$; dan $34,4^{\circ}$. Nilai $2 \theta$ ini merupakan ciri khas dari senyawa hidrotalsit $\mathrm{Mg} / \mathrm{Al}$ standar.

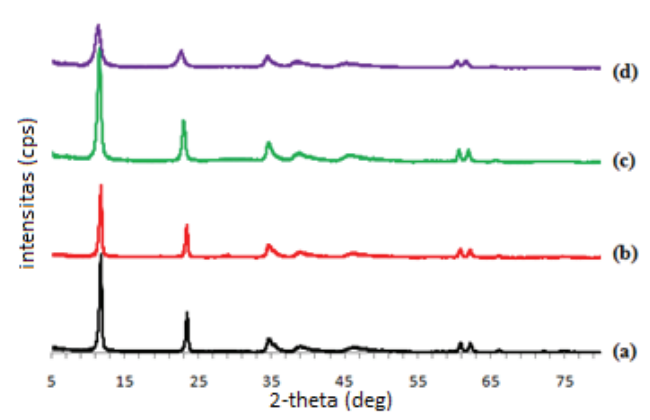

Gambar 2. Difraktogram XRD hidrotalsit Mg/Al (a) 1:1 (b) 2:1 (c) 3:1 (d) 4:1
(Gambar 2) menunjukkan bahwa hidrotalsit $\mathrm{Mg} / \mathrm{Al}$ dengan rasio 1, 2, 3, dan 4 diperoleh

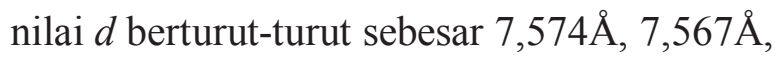
$7,701 \AA$, dan $7,807 \AA$. Hasil ini sesuai dengan penelitian Kloprogge [1] yang menunjukkan bahwa karakteristik hidrotalsit dengan anion antar lapis berupa $\mathrm{CO}_{3}{ }^{2-}$ dicirikan pada harga $d$ sekitar 7,80 $\AA$.

\section{Kesimpulan}

Berdasarkan hasil dan pembahasan maka dapat disimpulkan bahwa:

Variasi perbandingan mol $\mathrm{Mg} / \mathrm{Al}$ menyebabkan terjadinya perge-seran puncak pada difraktogram XRD bergeser kearah kiri seiring dengan meningkatnya perban-dingan rasio $\mathrm{mol} \mathrm{Mg} / \mathrm{Al}$, akan tetapi gugus-gugus fungsi utama pada senyawa hidrotalsit $\mathrm{Mg} / \mathrm{Al}$ semakin tidak terbentuk dengan baik.

\section{Pustaka}

Frost, R.L., Musumeci, A.W., Kloprogge, J.T., Weier, M.L., Adebajo, M.O. and Martens, W., 2006, Thermal Decomposition of Synthetic Hydrotalcites Reevesite and Pyroaurite, Journal of Thermal Analysis and Calorimetry, 86(1), 205209.

Heraldy, E., Pranoto., Dian, M., Khoirina D.N., Boshido, B.D., Imam,S., 2006, 
Studi Pengaruh Perbedaan Rasio Mol antara $\mathrm{Mg} / \mathrm{Al}$ dalam Sintesis $\mathrm{Mg} / \mathrm{Al}$ Hydrotalcite like, Alchemy Journal, 5, 54-59.

Kishore, D dan Kannan, S., 2004, Environmentally Begin Route for Isomerization of Safrole-Hydrotalcite as Solid Base Catalyst,Journal of Molecular Catalysis A: Chemical, 223, 225-230.

Kloprogge, J.T., Hickey, L., Frost, R.L., 2004, FT-Raman and FT-IR Spectroscopic Study of Synthetic $\mathrm{Mg} / \mathrm{Zn} / \mathrm{Al}$-Hydrotalcites, Journal of Raman Spectroscopy, 35, 967-974.

Kustrowski, P., Sulkwska D., Chmielarz, L., Lasocha, A., Dudek, B., Dziembaj, R.,2005, Influence of Thermal Treatment Conditions on the Activity of Hydrotalcite-derived $\mathrm{Mg}-\mathrm{Al}$ Oxides in the Aldol Condensation of Acetones, Microporous and Mesoporous Materials, 1, 11-22.

Narayanan, S. dan Krishna, K., 1998, Hydrotalcite Supported Palla-dium Catalysts Part I: Preparation, Characterization of Hydrotalcites and Palladium on Uncalcined Hydrotalcites for CO, Journal of
Applied Catalysis A: General, 174, 221-229.

Negron, G., Guerra, N., Lomas, L., Gavino, R., Cardenas, G., 2003,Calcined MgAl Hydrotalcites Catalyst in the Regioselective Synthesis of Silylated Vicinal Azidohydrins, Regional Issue "Organic Chemistry in Mexico.11, 179-184. 